\title{
Direct Oral Anticoagulants and Vitamin K Antagonists for Treatment of Deep Venous Thrombosis and Pulmonary Embolism in the Outpatient Setting: Comparative Economic Evaluation
}

\author{
Abdullah S Al Saleh, Patrick Berrigan, David Anderson, and Sudeep Shivakumar
}

\begin{abstract}
Background: To date, there have been few economic evaluations, from a Canadian perspective, of direct oral anticoagulants (DOACs) for the prevention of recurrent venous thromboembolism (VTE) in patients with acute unprovoked VTE. As a result, there is a lack of consensus about which treatment strategy should be adopted in the clinical setting.

Objectives: To assess the cost-effectiveness of currently approved anticoagulant options, in terms of cost per quality-adjusted life-year (QALY) gained, for the prevention of recurrent VTE in patients with unprovoked events managed on an outpatient basis.

Methods: Microsoft Excel was used to develop a Markov model. Model parameters were determined using published literature, local hospital data, expert opinion, and chart review. The analysis considered the costs associated with pharmaceuticals, laboratory testing, hematologist fees, and treatment of recurrent VTE and major bleeding events. Effectiveness was measured in terms of QALYs, and incremental cost-effectiveness ratios (ICERs) were calculated.

Results: For treatment lasting 3 months, apixaban represented the most cost-effective DOAC relative to low-molecular-weight heparin (LMWH) + vitamin K antagonist, with an ICER of \$7379.66. For 6 months of treatment, apixaban again represented the most cost-effective treatment, with an ICER of $\$ 84.08$ per QALY gained, and this drug dominated all the other strategies at 12 months. For lifetime treatment, DOACs were unlikely to be cost-effective, given a maximum willingness to pay of $\$ 50000$ to $\$ 100000$ per QALY. In a probabilistic sensitivity analysis at 6 months, $46.4 \%$ of iterations resulted in apixaban having lower costs and better outcomes than LMWH + vitamin K antagonist, and 78.6\% of iterations resulted in an ICER below $\$ 100000$
\end{abstract}

Conclusions: The findings of this study suggest that apixaban is likely cost-effective for treatment durations of 3, 6, and 12 months. However, for indefinite treatment, DOACs were unlikely to be cost-effective.

\section{RÉSUMÉ}

Contexte : À ce jour, on a réalisé peu d'évaluations économiques, d'un point de vue canadien, sur les anticoagulants oraux directs (AOD) utilisés dans la prévention de la thromboembolie veineuse (TEV) récurrente chez les patients atteints de TEV idiopathique aiguë. Pour cette raison, aucun consensus n'a été établi quant à la stratégie thérapeutique à adopter en milieu clinique.

Objectif : Évaluer le rapport coût-efficacité des anticoagulothérapies actuellement approuvées, en ce qui a trait au coût par année de vie pondérée par la qualité (QALY) gagnée, pour la prévention de la TEV récurrente chez les patients ayant subi des événements idiopathiques qui ont été traités en consultation externe.

Méthodes : Le logiciel Excel de Microsoft a servi à créer un modèle de Markov. Les paramètres du modèle ont été établis à l'aide de la littérature, de données de l'hôpital local, d'opinions d'experts et d'une analyse de dossiers médicaux. L'analyse prenait en compte les coûts associés aux médicaments, aux examens de laboratoire, aux honoraires d'hématologues et au traitement de la TEV récurrente et d'hémorragies importantes. L'efficacité était mesurée en nombre de QALY et les rapports coûtefficacité différentiels ont été calculés.

Résultats : Pour un traitement de trois mois, l'apixaban représentait l'AOD offrant le meilleur rapport coût-efficacité comparativement à l'héparine de bas poids moléculaire $(\mathrm{HBPM})+$ un antagoniste de la vitamine K; il présentait un rapport coût-efficacité différentiel de 7379,66 \$. Pour un traitement de six mois, l'apixaban représentait à nouveau le traitement le plus efficace par rapport au coût; il présentait un rapport coût-efficacité différentiel de 84,08 \$ par QALY gagnée. Ce médicament surclassait toutes les autres stratégies après douze mois de traitement. En ce qui concerne un traitement à vie, les AOD offraient probablement un moins bon rapport coût-efficacité, compte tenu d'une propension à payer maximale se situant entre 50000 \$ et 100000 \$ par 
Keywords: economic evaluation, cost-effectiveness, direct oral anticoagulants, venous thromboembolism

Can J Hosp Pharm. 2017;70(3):188-99
QALY. Dans une analyse de sensibilité probabiliste au sixième mois de traitement, $46,4 \%$ des itérations se traduisaient par des coûts moins élevés et de meilleurs résultats pour l'apixaban relativement à l'HBPM + un antagoniste de la vitamine K. De plus, 78,6 \% des itérations se traduisaient par un rapport coût-efficacité différentiel de moins de 100000 .

Conclusions : Ces résultats laissent croire que l'apixaban présente probablement un rapport coût-efficacité intéressant pour les traitements d'une durée de 3, 6 et 12 mois. Cependant, en ce qui concerne un traitement d'une durée indéterminée, les AOD ne sont sans doute pas avantageux.

Mots clés : évaluation économique, rapport coût-efficacité, anticoagulants oraux directs, thromboembolie veineuse

\section{INTRODUCTION}

$\mathrm{V}$ enous thromboembolism (VTE), which comprises deep venous thrombosis (DVT) and pulmonary embolism (PE), is a significant cause of morbidity and mortality worldwide. Standard treatment of VTE, using low-molecular-weight heparin (LMWH) overlapped with vitamin $\mathrm{K}$ antagonists (VKAs), is effective but requires frequent laboratory monitoring and has the potential for multiple drug and dietary interactions. In recent years, novel treatment strategies with direct oral anticoagulants (DOACs) have been increasing in popularity and availability. Three DOACs are approved for the treatment of VTE in Canada: dabigatran, rivaroxaban, and apixaban.

This study aimed to assess the cost-effectiveness of currently approved DOACs relative to LMWH + VKA in terms of cost per quality-adjusted life year (QALY) gained when administered to prevent recurrent VTE in patients with unprovoked VTE being managed on an outpatient basis. The analysis took the cost perspective of the health care payer.

\section{METHODS}

Microsoft Excel (Microsoft Corporation, Redmond, Washington) was used to develop a Markov model, a mathematical representation of medical care in which patients transition within a set of health states over simulated time intervals. Using a Markov model allowed the estimation of long-run health outcomes, accounting for patients who transition on and off anticoagulant therapy over time because of VTE recurrence. Determination of the model parameters was based on the published literature, local hospital data, expert opinion, and chart review. The chart review examined the 61 most recent patients who received treatment for acute unprovoked VTE between September 12, 2013, and January 6, 2016, at the Queen Elizabeth II Health Sciences
Centre in Halifax, Nova Scotia. Ethics approval was received from the Nova Scotia Health Authority Research Ethics Board, which waived the need for informed consent.

In the study model, a hypothetical cohort of patients received one of the following treatments: apixaban, LMWH in combination with dabigatran (LMWH + dabigatran), rivaroxaban, or LMWH + VKA. Patients in the apixaban group received $10 \mathrm{mg}$ of the drug twice daily for 7 days, followed by $5 \mathrm{mg}$ twice daily thereafter. Patients in the LMWH + dabigatran group received LMWH for 6 days, followed by $150 \mathrm{mg}$ of dabigatran twice daily thereafter. Patients in the rivaroxaban group received $15 \mathrm{mg}$ of the drug twice daily for 21 days, followed by $20 \mathrm{mg}$ daily thereafter. Patients in the LMWH + VKA group received LMWH for 6 days overlapped with VKA. Patients receiving DOACs underwent yearly assessment of renal function by creatinine clearance testing. Patients receiving VKA underwent international normalized ratio (INR) testing to ensure that the drug effect remained within the therapeutic range. INR testing and changes to VKA dosage were initially overseen by a registered nurse specializing in hematology, but once INR remained within the therapeutic range for 2 values, care was transferred to the patient's family doctor. All patients underwent a complete blood count (CBC) at the start of treatment, and patients taking $\mathrm{LMWH}$ underwent a second $\mathrm{CBC}$ at 1 week. All patients received consultations with a hematologist initially, then at 1 week and 6 months, and then yearly if they continued anticoagulant therapy (Figure 1). The Markov model assumed 4 health states: recurrent VTE, major bleeding event, death, and no adverse health event (Figure 2).

The model used 6-month Markov cycles over a lifetime follow-up period. Effectiveness was measured with QALY, a metric expressing the extent to which an individual's health affects length and quality of life. ${ }^{1}$ The analysis considered costs associated with pharmaceuticals, laboratory testing, hematologist fees, 


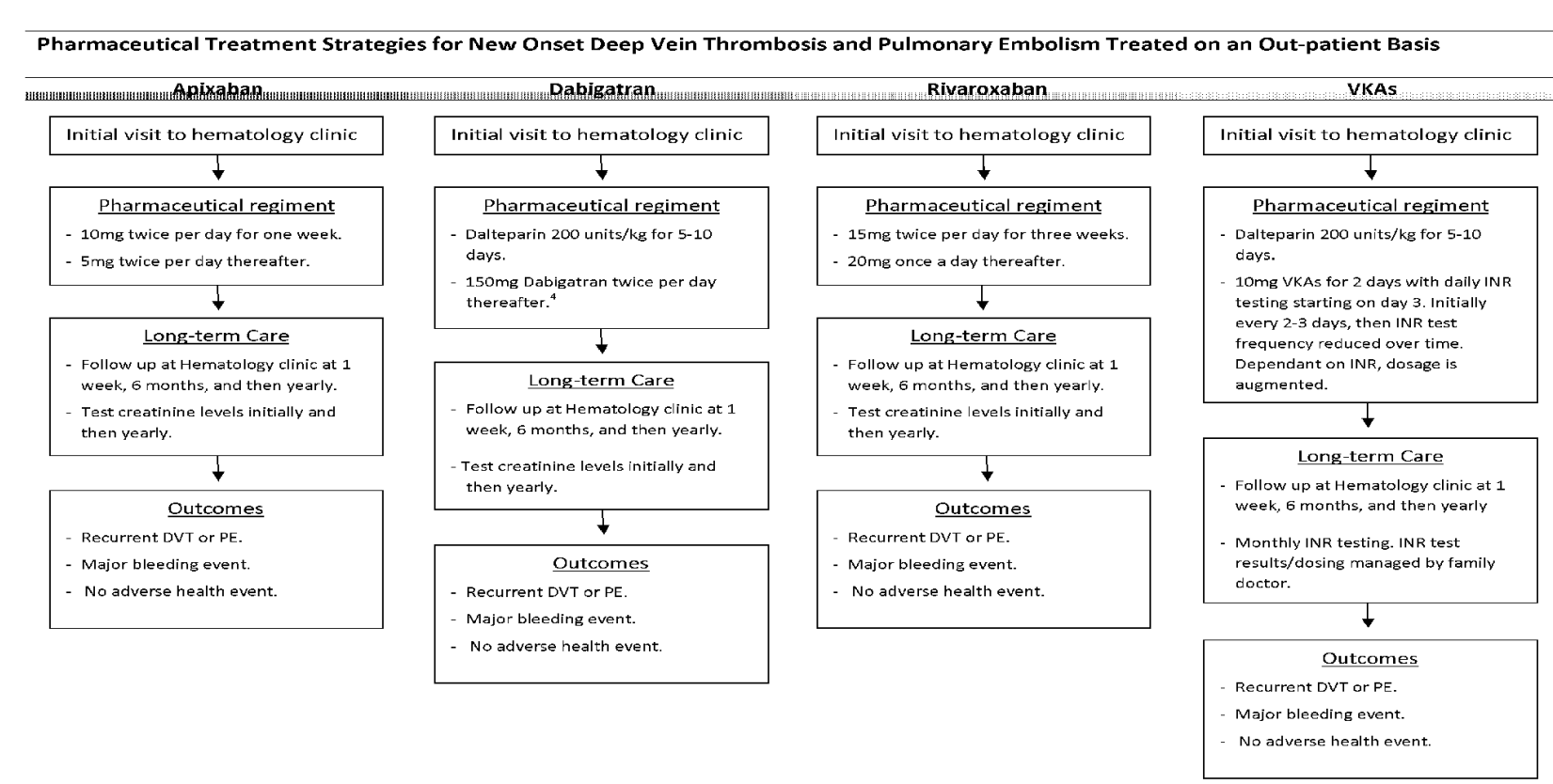

Figure 1. Pharmaceutical-specific treatment strategies. DVT = deep venous thrombosis, INR = international normalized ratio, $\mathrm{PE}=$ pulmonary embolism, VKA = vitamin $\mathrm{K}$ antagonist.

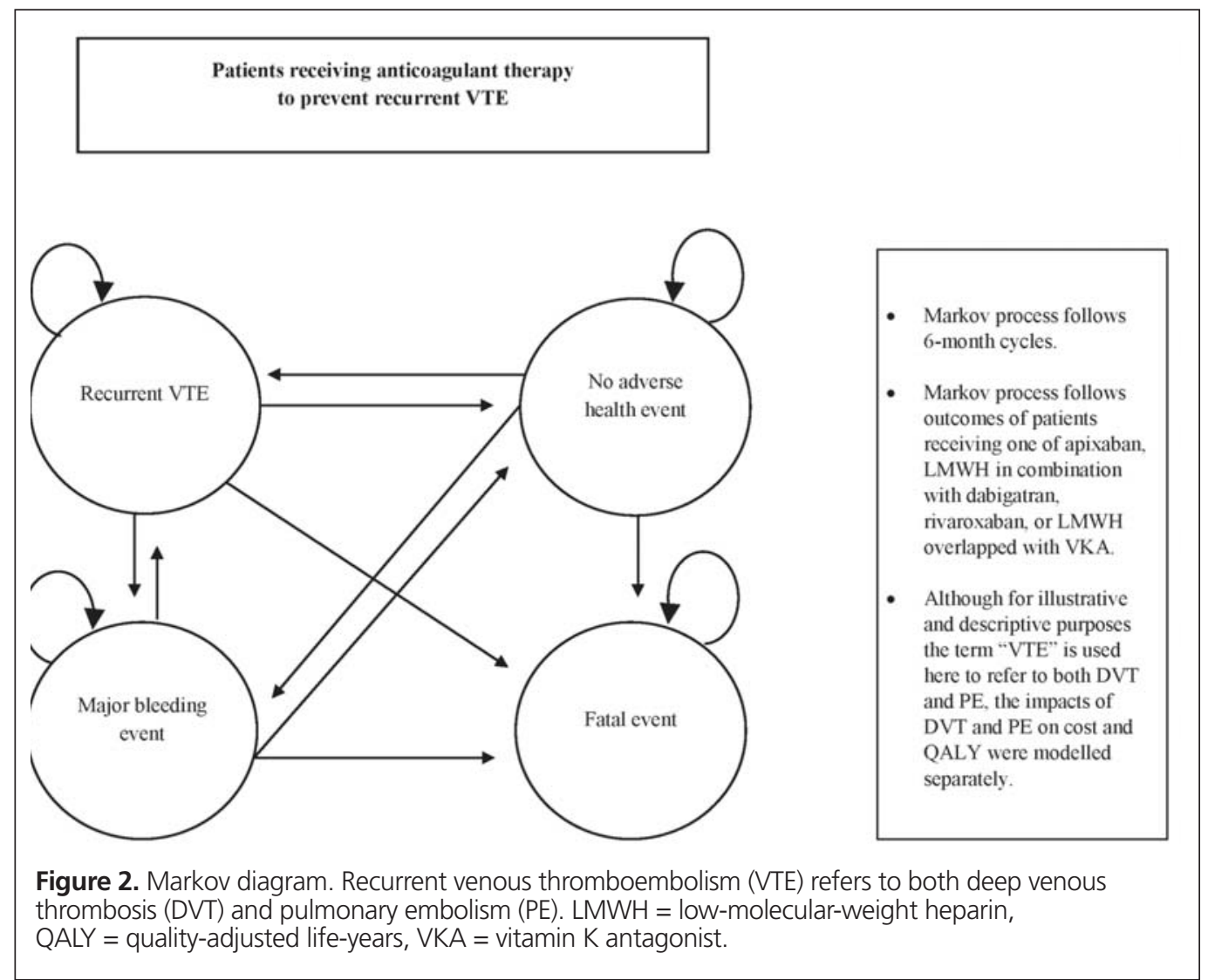


recurrent VTE, and major bleeding events. Incremental costeffectiveness ratios (ICERs), representing the cost required to gain an additional outcome when comparing 2 interventions, were calculated. ${ }^{2}$

The reference case used 6 months of anticoagulant therapy, because this represents a frequently used treatment duration in the clinical setting and the most common duration at the study hospital. ${ }^{3}$ Alternative analyses were also conducted, using 3-month, 12-month, and lifetime treatment durations. These alternative durations were chosen because they are also commonly used to treat patients with unprovoked VTE. ${ }^{3}$ In addition to the cost-effectiveness analysis, a cost-minimization analysis was conducted, on the assumption that all interventions are equivalent in terms of effectiveness and safety. The Canadian Agency for Drugs and Technologies in Health (CADTH), in its Guidelines for the Economic Evaluation of Health Technologies, ${ }^{4}$ recommends cost-minimization analysis if the interventions under review are equivalent in terms of effectiveness and safety.

\section{Hypothetical Cohort}

The average age at initial diagnosis was assumed to be 57 years, and the proportion of women was assumed to be $43 \%$. These assumptions were based on patients in studies investigating apixaban, dabigatran, or rivaroxaban referenced by Castellucci and others ${ }^{5}$ in their systematic review and meta-analysis examining the efficacy and safety of pharmaceuticals used to prevent recurrent VTE.

\section{Pharmaceutical Costs}

Costs for apixaban, rivaroxaban, dabigatran, dalteparin (an LMWH), and VKA were taken from the pharmacy at the study hospital and reflect the price paid by patients. The price per day of apixaban was $\$ 8.03$ for the first 7 days and $\$ 4.01$ thereafter. The price per day of rivaroxaban was $\$ 6.99$ for the first 21 days and $\$ 3.61$ thereafter. The price per day of dabigatran was $\$ 4.01$. Dosages of LMWH and VKA must be individualized, because a number of factors can influence their therapeutic effect. The chart review showed that patients received on average 18114.75 units (standard deviation [SD] 8601.84) of dalteparin daily, which corresponds to a cost of $\$ 43.10$ per day for an average of 5.72 days (SD 1.32 days). To calculate the cost of VKA, care was segmented into 2 periods: the first being the period when dosing is managed by a registered nurse and the second being the period when dosing is managed by the patient's family doctor. The chart review showed that on average the first period lasted 42.5 days (SD 23.6), with patients receiving an average daily dose of $5.75 \mathrm{mg}$ (SD $2.17 \mathrm{mg}$ ), which corresponds to a cost of $\$ 0.70$ per day. When care was transferred to the family doctor, the patient's VKA dose for the first period was used to approximate the daily dose of VKA over the second period. The chart review showed that at the time of transfer, patients were receiving on average $5.77 \mathrm{mg}$ (SD $2.76 \mathrm{mg}$ ) of VKA daily, which corresponded to a cost of $\$ 0.70$ per day. A portion of the patients who were receiving LMWH required home care nursing, because they were unable to self-inject. According to previous Canadian economics literature, ${ }^{6,7}$ a value of $19 \%$ was used to estimate the percentage of patients requiring assistance with injections. ${ }^{8}$ The cost of a home care nursing visit was estimated at $\$ 40.00$ (Victorian Order of Nurses, personal communication by telephone, December 7 , 2015).

\section{Monitoring Costs}

The cost of laboratory testing reflects technician wages and the cost of reagents at the study hospital. The costs were $\$ 3.85$ for each INR test, $\$ 2.77$ for each CBC, and $\$ 1.12$ for each creatinine clearance test. The cost of interpreting INR results and adjusting VKA dosage differed depending on the health care provider performing the service. The median compensation to a registered nurse within the hospital was $\$ 44.72$ per hour, including wages, benefits, and obligatory employer contributions. ${ }^{9}$ Nurses were interviewed to determine the time required to interpret INR and adjust VKA dosages, and estimated an average of 3 minutes per INR, which corresponds to a cost of $\$ 2.24$. The Medical Services Insurance (MSI) Physician's Manual ${ }^{10}$ lists a general practitioner's compensation for anticoagulant management as $\$ 24.20$ per month.

\section{Hematologist Fees}

The MSI Physician's Manual ${ }^{10}$ lists compensation for an initial consultation with a hematologist as $\$ 150.04$ and compensation for a follow-up consultation as $\$ 66.31$.

\section{Outcome Costs}

At the study hospital, most of the patients who experience recurrent VTE receive outpatient care equivalent to care after their initial VTE. However, we estimated that $10 \%$ of patients with recurrent VTE require inpatient care. Patients requiring inpatient care receive a daily visit from a hospital-based general practitioner and 8 additional INR tests after discharge, as well as initial and follow-up consultations with a hematologist. According to the Canadian Institute for Health Information, ${ }^{11}$ the average hospital costs for inpatient DVT and PE care, not including physician fees, are $\$ 6730.38$ and $\$ 7590.18$ with average lengths of stay of 6.3 and 5.9 days, respectively. The cost and length of stay for PE represent data for non-DVT embolisms. According to the MSI Physician's Manual, ${ }^{10}$ a hospital-based general practitioner receives $\$ 31.46$ per consultation. Combining the hospital costs of inpatient care, postdischarge INR tests, and general practitioner or hematologist fees results in a total cost of $\$ 7192.71$ per recurrent DVT and $\$ 8039.92$ per recurrent PE. For the reference 
case and the 3- and 12-month scenarios, patients who experienced recurrent VTE after cessation of anticoagulant therapy received 6 months of the same anticoagulant they received after the initial VTE, which would be the minimum duration at the study hospital for a recurrent event, with reassessment at that time for lifetime anticoagulant therapy. Patients receiving lifetime anticoagulant therapy would continue treatment as planned. Costs of major bleeding events were estimated on the basis of McDonald and others, ${ }^{7}$ who reported costs of $\$ 10904.56$ for nonfatal major bleeding events and \$40 214.73 for fatal major bleeding events in patients who had undergone hip or knee replacement. ${ }^{12}$ The cost of fatal recurrent VTE was assumed to be the same as the cost for nonfatal recurrent PE requiring inpatient care. Costs were converted to 2014 Canadian dollars using Statistics Canada's Consumer Price Index. ${ }^{13}$

\section{Outcome Rates}

Outcome rates were modelled using 2 time periods, the first being the first Markov cycle after the initial VTE (representing short-run outcome rates) and the second being all successive Markov cycles thereafter (representing long-run outcome rates). If a patient experienced recurrent VTE, the short-run outcome rates were applied to the Markov cycle in which the recurrent VTE occurred, with transition to the long-run outcome rates for Markov cycles thereafter. There was no limit to the number of adverse health events that a patient could experience. Rates of VTE and major bleeding events were determined using the number of events reported in literature. If VTE was not confirmed as the cause of death, the incident was not included in fatality rates for this analysis. Patients who experienced both recurrent DVT and PE were classified as having experienced PE.

To estimate pharmaceutical-specific outcome rates for the first Markov cycle, we pooled the findings of studies presented in Castellucci and others ${ }^{5}$ investigating apixaban, dabigatran, or rivaroxaban. In the following summary of these studies, the percentage of fatal events is presented in parentheses after rates of recurrent PE and major bleeding events. Agnelli and others ${ }^{14}$ compared apixaban with LMWH + VKA in a total of 2691 patients, with $0.74 \%$ experiencing recurrent DVT, 1.04\% (3.57\%) experiencing recurrent PE, and $0.56 \%$ (6.67\%) experiencing a major bleeding event. Schulman and others ${ }^{15,16}$ compared LMWH + dabigatran with LMWH + VKA in 1274 and 1279 patients, respectively. Combining the findings of these 2 studies yielded a recurrent DVT rate of $1.61 \%$, a recurrent PE rate of $0.94 \%(16.67 \%)$, and a major bleeding event rate of $1.37 \%(2.86 \%)$. Bauersachs and others ${ }^{17}$ and Büller and others ${ }^{18}$ compared rivaroxaban with LMWH + VKA in 2419 and 1731 patients, respectively. Combining the findings of these studies yielded a recurrent DVT rate of $0.77 \%$, a recurrent PE rate of $1.11 \%(6.52 \%)$, and a major bleeding event rate of $0.96 \%$
(7.50\%). To estimate outcome rates for LMWH + VKA, we pooled the findings of studies presented in Castellucci and others ${ }^{5}$ investigating apixaban, dabigatran, or rivaroxaban and using LMWH + VKA as the control intervention, ${ }^{14-18}$ which resulted in a recurrent DVT rate of $1.20 \%$, a recurrent $\mathrm{PE}$ rate of $0.94 \%$ $(6.82 \%)$, and a major bleeding event rate of $1.78 \%(7.19 \%)$ in a total of 9389 patients.

To estimate pharmaceutical-specific outcome rates for long-run Markov cycles, we pooled the findings of studies investigating extended-use DOACs to prevent recurrent VTE identified in a literature review. ${ }^{17,19,20}$ Long-run outcome rates were converted to reflect 6-month rates. Agnelli and others ${ }^{19}$ compared apixaban with placebo in a total of 813 patients, with $0.45 \%$ experiencing recurrent DVT, $0.23 \%$ (0\%) experiencing recurrent $\mathrm{PE}$, and $0.06 \%(0 \%)$ experiencing a major bleeding event. Schulman and others ${ }^{20}$ compared dabigatran with VKA in 1430 patients and compared dabigatran with placebo in 681 patients. Combining the findings of these 2 studies yielded a recurrent DVT rate of $0.15 \%$, a recurrent PE rate of $0.09 \%$ (8.33\%), and a major bleeding event rate of $0.12 \%(0 \%)$. Bauersachs and others $^{17}$ compared rivaroxaban with placebo in a total of 602 patients, with $0.50 \%$ experiencing recurrent DVT, $0.20 \%$ (0\%) experiencing recurrent $\mathrm{PE}$, and $0.40 \%(0 \%)$ experiencing a major bleeding event. To estimate long-run outcome rates in patients receiving VKA, we used the findings of Schulman and others, ${ }^{20}$ who used VKA in 1426 patients in the control arm of their study. Schulman and others ${ }^{20}$ reported $0.15 \%$ experiencing recurrent DVT, 0.07\% (16.67\%) experiencing recurrent PE, and 0.29\% (4.00\%) experiencing a major bleeding event.

To approximate long-run outcome rates in patients who discontinued anticoagulant therapy in the reference case and the 3-month and 12-month scenarios, we used the outcome rates for patients receiving placebo in the extended trials. ${ }^{17,19,20}$ Combining the results of these studies yielded a recurrent DVT rate of $2.40 \%$, recurrent PE rate of $0.98 \%$ (4.65\%), and major bleeding event rate of $0.07 \%(0 \%)$ in a total of 2085 patients.

\section{Health-Related Quality of Life}

On the basis of previous Canadian economic literature, ${ }^{6,7}$ we applied utility scores of 0.84 for recurrent DVT, 0.76 for recurrent $\mathrm{PE}$, and 0.66 for major bleeding events. ${ }^{21-23}$ Disutility associated with adverse health events was assumed to last for 3 months, ${ }^{6,7}$ and a healthy patient was assumed to have a utility score of $1 .^{6,7,24}$

\section{Background Mortality}

Background mortality was estimated by applying a standardized mortality ratio of 2.0 to the expected mortality in the general Canadian population. ${ }^{25}$ The standardized mortality ratio of 2.0 was chosen based on the findings of a cohort study investigating long-run mortality in VTE patients. ${ }^{26}$ 


\section{Discounting and Follow-up}

Cost and QALY were discounted at a rate of 5\%, and sensitivity analyses were conducted with rates of $0 \%$ and $3 \%$. In the reference case and alternative analyses, costs and QALY were aggregated for 25 years, representing a lifetime follow-up period..$^{25}$

\section{Sensitivity Analyses}

One-way sensitivity analysis was conducted using the ICER associated with the upper and lower bounds of the probabilistic sensitivity analysis (PSA) intervals for key parameters (Table 1). Each DOAC was compared with LMWH + VKA in the reference case, and the results are presented in a tornado plot.

\section{Table 1 (part 1 of 2). Parameter Estimates, PSA Intervals, and Distributions*}

\begin{tabular}{|c|c|c|c|}
\hline \multirow{2}{*}{$\frac{\text { Parameter [Data Source] }}{\text { Pharmaceutical costs, \$ }}$} & \multicolumn{2}{|c|}{ Estimate (PSA Interval) } & \multirow[t]{2}{*}{ Distributiont } \\
\hline & & & \\
\hline Apixaban: first 7 days [HP] & 8.03 & $(6.02-10.04)$ & Uniform \\
\hline Apixaban: after first 7 days [HP] & 4.01 & $(3.01-5.01)$ & Uniform \\
\hline Dabigatran [HP] & 4.01 & $(3.01-5.01)$ & Uniform \\
\hline Rivaroxaban: first 21 days [HP] & 6.99 & $(5.24-8.74)$ & Uniform \\
\hline Rivaroxaban: after first 21 days [HP] & 3.61 & $(2.71-4.51)$ & Uniform \\
\hline LMWH (dalteparin) [HP] & 43.10 & $(37.86-48.34)$ & Log-normal \\
\hline Time taking LMWH (days) [CR] & 5.72 & $(5.38-6.06)$ & Log-normal \\
\hline Cost of home care $[\mathrm{PC}]$ & 40.00 & $(30.00-50.00)$ & Uniform \\
\hline$\%$ of patients requiring home care ${ }^{8}$ & 19 & $(11.5-28.8)$ & Beta \\
\hline \multicolumn{4}{|l|}{ Daily cost of VKA [HP] } \\
\hline While under care of hematologist & 0.70 & $(0.53-0.88)$ & Uniform \\
\hline While under care of general practitioner & 0.70 & $(0.53-0.88)$ & Uniform \\
\hline \multicolumn{4}{|l|}{ Costs of laboratory tests, \$ } \\
\hline Complete blood count [LH] & 2.77 & $(2.08-3.46)$ & Uniform \\
\hline INR [LH] & 3.85 & $(2.89-4.81)$ & Uniform \\
\hline Creatinine clearance $[\mathrm{LH}]$ & 1.12 & $(0.84-1.40)$ & Uniform \\
\hline \multicolumn{4}{|l|}{ Health care provider costs, $\$$} \\
\hline Initial consultation with hematologist ${ }^{10}$ & 150.04 & $(112.53-187.55)$ & Uniform \\
\hline Follow-up consultation with hematologist ${ }^{10}$ & 66.31 & $(49.73-82.89)$ & Uniform \\
\hline \multicolumn{4}{|l|}{ Interpretation of INR results and management of VKA dosing } \\
\hline By general practitioner, per month ${ }^{10}$ & 24.20 & $(18.15-30.25)$ & Uniform \\
\hline By registered nurse ${ }^{9}$ & 44.72 & $(33.54-55.90)$ & Uniform \\
\hline Time required by nurse, min [EO] & 3 & $(1-5)$ & Uniform \\
\hline No. of INRs managed by hematology nurse, mean [CR] & 7.85 & $(7.06-8.65)$ & Log-normal \\
\hline \multicolumn{4}{|l|}{ Outcome costs, \$ } \\
\hline Recurrent DVT in inpatient ${ }^{9-11}[\mathrm{HP}, \mathrm{LH}, \mathrm{CR}]$ & 7192.71 & $(5395-8991)$ & Log-normal \\
\hline$\%$ treated as inpatient [EO] & 10 & $(7.5-12.5)$ & Uniform \\
\hline Recurrent PE in inpatient t-11 $\left.^{9-\mathrm{HP}}, \mathrm{LH}, \mathrm{CR}\right]$ & 8039.92 & $(6030-10050)$ & Log-normal \\
\hline$\%$ treated as inpatient [EO] & 10 & $(7.5-12.5)$ & Uniform \\
\hline Fatal recurrent $\mathrm{PE}^{9-11}[\mathrm{HP}, \mathrm{LH}, \mathrm{CR}]$ & 8039.92 & $(6030-10050)$ & Log-normal \\
\hline Bleeding event ${ }^{7}$ & 10905 & $(8179-13631)$ & Log-normal \\
\hline Fatal bleeding event ${ }^{7}$ & 40215 & (30 161-50 269) & Log-normal \\
\hline \multicolumn{4}{|l|}{ Outcome rates, first cycle, $\%$} \\
\hline \multicolumn{4}{|l|}{ Apixaban ${ }^{14}$} \\
\hline Recurrent DVT & 0.74 & $(0.46-1.15)$ & Beta \\
\hline Recurrent PE & 1.04 & $(0.69-1.50)$ & Beta \\
\hline Bleeding event & 0.56 & $(0.31-0.92)$ & Beta \\
\hline \multicolumn{4}{|l|}{ Dabigatran ${ }^{15,16}$} \\
\hline Recurrent DVT & 1.61 & $(1.16-2.17)$ & Beta \\
\hline Recurrent PE & 0.94 & $(0.60-1.40)$ & Beta \\
\hline Bleeding event & 1.37 & $(0.96-1.90)$ & Beta \\
\hline \multicolumn{4}{|l|}{ Rivaroxaban ${ }^{17,18}$} \\
\hline Recurrent DVT & 0.77 & $(0.53-1.09)$ & Beta \\
\hline Recurrent PE & 1.11 & $(0.81-1.48)$ & Beta \\
\hline Bleeding event & 0.96 & $(0.69-1.31)$ & Beta \\
\hline \multicolumn{4}{|l|}{$V_{K} A^{14-18}$} \\
\hline Recurrent DVT & 1.20 & $(0.99-1.44)$ & Beta \\
\hline Recurrent PE & 0.94 & $(0.75-1.15)$ & Beta \\
\hline Bleeding event & 1.78 & $(1.52-2.07)$ & Beta \\
\hline
\end{tabular}


Table 1 (part 2 of 2). Parameter Estimates, PSA Intervals, and Distributions*

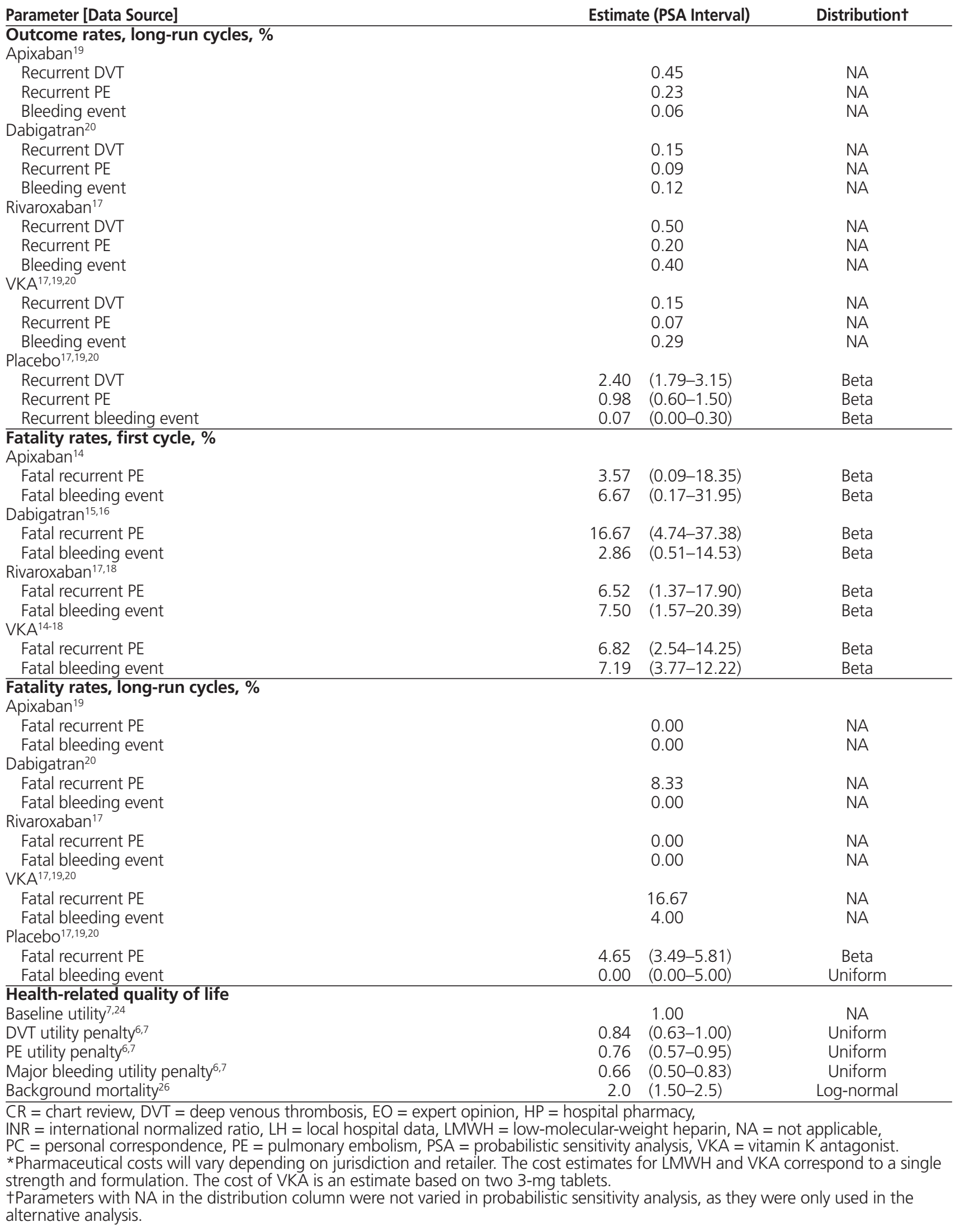


Table 2A. Internal Validation of Model

\begin{tabular}{lcc} 
Parameter & $\begin{array}{c}\text { Parameter Value } \\
\text { Estimate (\%)* }\end{array}$ & Present Study (\%)† \\
\hline Recurrent VTE & $1.78-2.55^{14-21}$ & $1.76-2.53$ \\
6 months from initial VTE & $5.16-5.93^{14-21}$ & $5.05-5.82$ \\
\hline 12 months from initial VTE & & $0.55-1.76$ \\
\hline Major bleeding event & $0.56-1.78^{14-21}$ & $0.63-1.87$ \\
\hline months from initial VTE & $0.63-1.85^{14-21}$ &
\end{tabular}

$\mathrm{VTE}=$ venous thromboembolism.

* Literature-derived parameter estimates that informed the decision model.

tRange of outcomes predicted by the model across pharmaceuticals used in the reference case scenario.

Table 2B. External Validation of Model (Probability of Occurrence)

\begin{tabular}{|c|c|c|c|}
\hline $\begin{array}{l}\text { Outcome at } \\
10 \text { Years from } \\
\text { Initial VTE }\end{array}$ & $\begin{array}{l}\text { Observed Value } \\
\text { (Literature)* }\end{array}$ & $\begin{array}{r}\text { Klare } \\
\text { et a }\end{array}$ & Present Studył \\
\hline Recurrent VTE, \%§ & $6-$ & 4.1 & 12 \\
\hline All-cause mortality, \% & $8.5^{31}$ & $29.1-30.2$ & \\
\hline \multicolumn{4}{|c|}{$\begin{array}{l}\text { VTE }=\text { venous thromboembolism. } \\
\text { * Outcome rates observed in the literature. } \\
\text { tRanges of values predicted by Klarenbach and others }{ }^{28} \text { and presented in their model validation } \\
\text { That previous economic evaluation represents the position of the Canadian Agency for Drugs } \\
\text { and Technology in Health on the use of direct oral anticoagulants for the treatment of venous } \\
\text { thromboembolism. } \\
\neq \text { Range of outcomes predicted by the model across pharmaceuticals used in the reference case } \\
\text { scenario. } \\
\S \text { Does not include recurrent VTE observed during the initial period of anticoagulant therapy. }\end{array}$} \\
\hline
\end{tabular}

Table 3. Cost-Effectiveness Results for Reference Case and Alternative Models

\begin{tabular}{|c|c|c|c|c|c|}
\hline Intervention & $\begin{array}{c}\text { Cost per } \\
100 \text { Patients, \$ }\end{array}$ & $\begin{array}{l}\text { QALY per } \\
100 \text { Patients }\end{array}$ & $\begin{array}{l}\text { Cost Difference } \\
\text { per } 100 \text { Patients, \$ }\end{array}$ & $\begin{array}{c}\text { QALY } \\
\text { Difference per } \\
100 \text { Patients }\end{array}$ & ICER, * \$ \\
\hline \multicolumn{6}{|l|}{$\begin{array}{l}\text { 6-month therapy } \\
\text { (reference case) }\end{array}$} \\
\hline LMWH + VKA & 253754.40 & 1011.33 & NA & NA & NA \\
\hline LWMH + dabigatran & 310450.94 & 1011.32 & 56696.53 & -0.01 & Dominated \\
\hline Rivaroxaban & 258016.85 & 1012.27 & 4262.45 & 0.95 & Dominated \\
\hline Apixaban & 253930.44 & 1013.42 & 176.03 & 2.09 & 84.08 \\
\hline \multicolumn{6}{|l|}{ 3-month therapy } \\
\hline LMWH +VKA & 242514.35 & 1012.45 & NA & NA & NA \\
\hline LWMH + dabigatran & 302824.47 & 1012.22 & 60310.12 & -0.23 & Dominated \\
\hline Rivaroxaban & 252349.93 & 1012.95 & 9835.58 & 0.50 & Dominated \\
\hline Apixaban & 251192.21 & 1013.62 & 8677.86 & 1.18 & 7379.66 \\
\hline \multicolumn{6}{|l|}{ 12-month therapy } \\
\hline LMWH + VKA & 250704.28 & 1011.82 & NA & NA & NA \\
\hline LWMH + dabigatran & 304329.00 & 1011.98 & 53624.72 & 0.16 & Dominated \\
\hline Rivaroxaban & 256512.59 & 1012.91 & 5808.32 & 1.08 & Dominated \\
\hline Apixaban & 248878.34 & 1014.09 & -1825.93 & 2.27 & Dominant strategy \\
\hline \multicolumn{6}{|l|}{ Lifetime therapy } \\
\hline LMWH + VKA & 842389.43 & 1020.16 & NA & NA & NA \\
\hline LWMH + dabigatran & 1705856.10 & 1022.94 & 863466.66 & 2.78 & Dominated \\
\hline Rivaroxaban & 1596345.37 & 1022.88 & 753955.93 & 2.72 & 277107.39 \\
\hline Apixaban & 1668152.46 & 1024.89 & 825763.02 & 4.73 & 174614.23 \\
\hline
\end{tabular}

ICER = incremental cost-effectiveness ratio, LMWH = low-molecular-weight heparin, NA = not applicable,

QALY = quality-adjusted life years, VKA = vitamin $\mathrm{K}$ antagonist.

* "Dominated " refers to at least one competing strategy having both superior outcomes and lower costs. "Dominant strategy" refers to both superior outcomes and lower costs relative to all other competing strategies. 
PSA was conducted by simultaneously varying all parameter estimates in the reference case within relevant intervals, subject to statistical distributions. Once each parameter value was varied, the subsequent ICER was recorded. This process was repeated 10000 times. Parameter intervals and distributions used in creating the model are presented in Table 1.

PSA intervals for the percentage of patients requiring home care and outcome rates represented 95\% confidence intervals taken from the literature or calculated using the method of Clopper and Pearson. ${ }^{27}$ The intervals related to pharmaceutical costs (with the exception of LMWH), laboratory testing, health care provider reimbursements, health outcome costs, standardized mortality ratio, and health-related quality of life represent $\pm 25 \%$ of the parameter value estimate. PSA intervals for LMWH and the average number of INR tests managed by a registered nurse represent $95 \%$ confidence intervals determined from the chart review.

\section{Model Validation}

To assess internal validity, the literature-derived parameter estimates used to inform the model for key outcomes were compared with the model's predicted values for the corresponding outcomes. To assess external validity, values observed in the literature for key outcomes were compared with those predicted by the model. ${ }^{28-30}$

\section{RESULTS}

In terms of internal validation, model predictions were similar to the literature-derived parameter estimates (Table 2A). In terms of external validation, the model predicted similar mortality rates to those observed in previous literature ${ }^{28,30}$ but higher rates of recurrent VTE ${ }^{28}$ (Table 2B).

In the reference case, apixaban dominated the other DOACs (i.e., had superior costs and outcomes) and had an ICER of $\$ 84.08$ relative to LMWH + VKA (Table 3). A discount rate of $0 \%$ resulted in apixaban dominating all other strategies, and a discount rate of $3 \%$ resulted in apixaban dominating the other DOACs and having an ICER of $\$ 36.79$ relative to LMWH + VKA (Table 3).

Alternative analyses were conducted using 3-month, 12-month, and lifetime durations of anticoagulant therapy. For 3-month duration, apixaban dominated the other DOACs and had an ICER of $\$ 7379.66$ relative to LMWH + VKA. For 12-month duration, apixaban dominated all other strategies. For lifetime duration, apixaban had the lowest ICER of any DOAC, at $\$ 174614.23$ (Table 3).

This cost-minimization analysis found that LMWH + VKA was the least costly strategy when considering non-outcomerelated costs for treatment duration lasting 6 months or longer. For 3-month treatment durations, DOACs not requiring LMWH were the least costly.
One-way sensitivity analysis suggested that short-run fatality rates and pharmaceutical costs were the largest drivers of uncertainty in the current analysis (Figure 3).

Using the 10000 PSA iterations, a cost-effectiveness acceptability curve was constructed (Figure 4). This type of curve uses PSA iterations to provide decision-makers with a degree of certainty regarding an intervention's cost-effectiveness relative to another intervention. The curve depicts the percentage of PSA iterations that fall below a given willingness-to-pay for the outcome of interest. Figure 5 shows the cost-effectiveness plane, plotting the change in QALY on the horizontal axis versus the change in cost on the vertical axis for each of the 10000 iterations. Decision-makers can use the cost-effectiveness plane to gain additional insight into an intervention's cost-effectiveness, by examining the quadrants into which the bulk of PSA iterations fall. The upper quadrants reflect higher costs, and quadrants on the right represent superior outcomes associated with a new intervention (in Figure 5, apixaban is the new intervention). The cost-effectiveness acceptability curve compared apixaban with LMWH + VKA in the reference case: $46.4 \%$ of iterations resulted in apixaban dominating LMWH + VKA; 78.6\% of iterations resulted in ICER below $\$ 100000 ; 97.1 \%$ of iterations resulted in apixaban generating more QALY; and $47.2 \%$ of PSA iterations resulted in apixaban being cost-saving.

\section{DISCUSSION}

Few Canadian economic evaluations have compared currently approved DOACs with LMWH + VKA for the treatment of unprovoked VTE. Klarenbach and other ${ }^{28}$ compared DOACs with LMWH + VKA and reported that the ICERs associated with DOACs were too high to be considered attractive. Quon and others ${ }^{31}$ compared LMWH + dabigatran, rivaroxaban, and LMWH + VKA with apixaban for extended treatment in preventing recurrent VTE and found that apixaban was the dominant strategy for 3-and 6-month durations of anticoagulant therapy and was a cost-effective alternative to LMWH + VKA for 18-month and lifetime durations of anticoagulant therapy.

Klarenbach and others ${ }^{28}$ presented CADTH's position on the cost-effectiveness of DOACs for the treatment of VTE. Because CADTH is Canada's national authority on the economic evaluation of health technologies, it is important to discuss how differences in model assumptions between the current study and that of Klarenbach and others ${ }^{28}$ may have led to differing results. From a cost perspective, the most important difference between the current study and the existing literature was the application of a pharmaceutical cost of $\$ 0.70$ per day for VKA, rather than the $\$ 0.11$ used in previous studies. ${ }^{28,31}$ With respect to effectiveness, the current study found that DOACs (most notably apixaban) were more effective at generating QALY relative to LMWH + VKA than was the case in the previous literature. ${ }^{28,31}$ This difference probably stems from the assumption in the current 


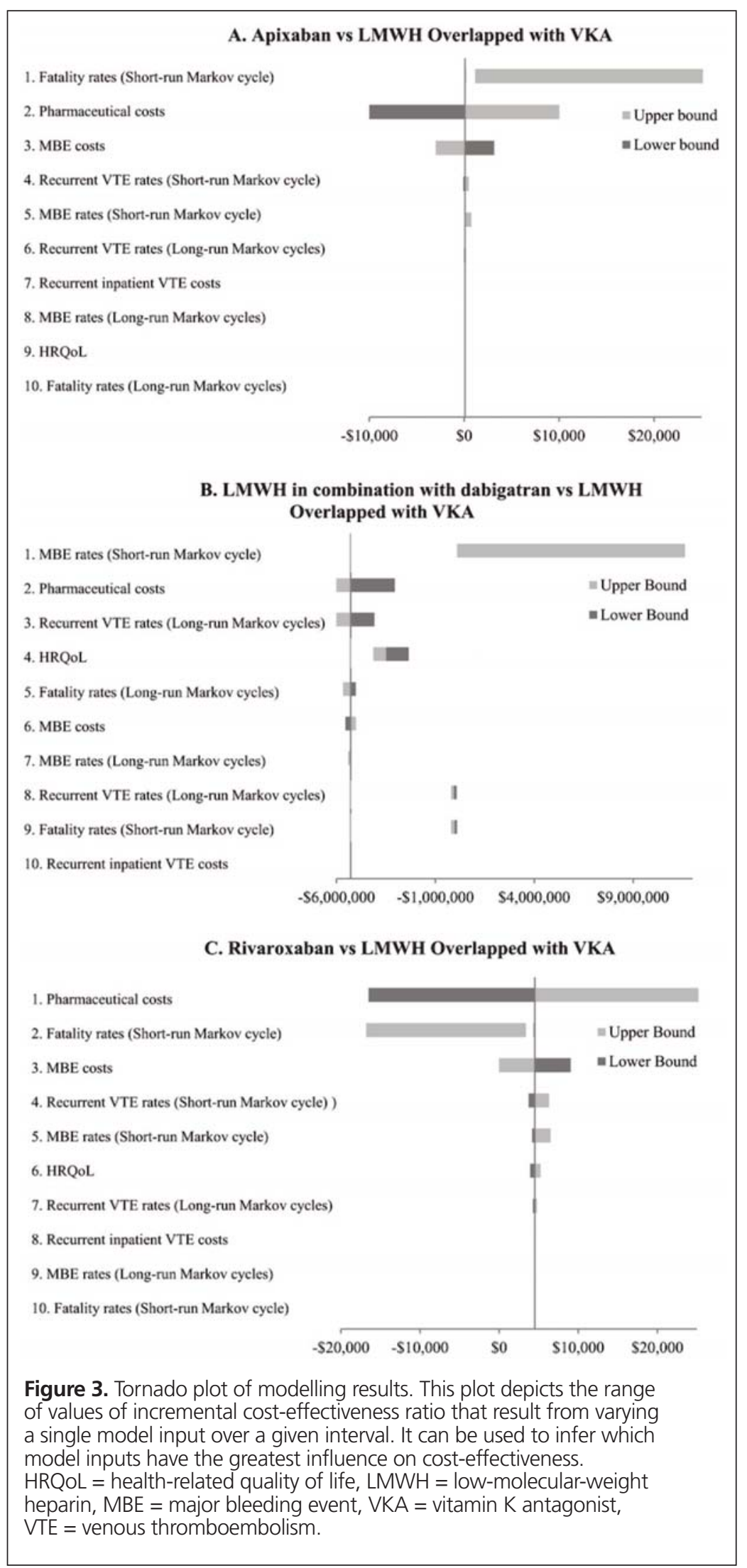




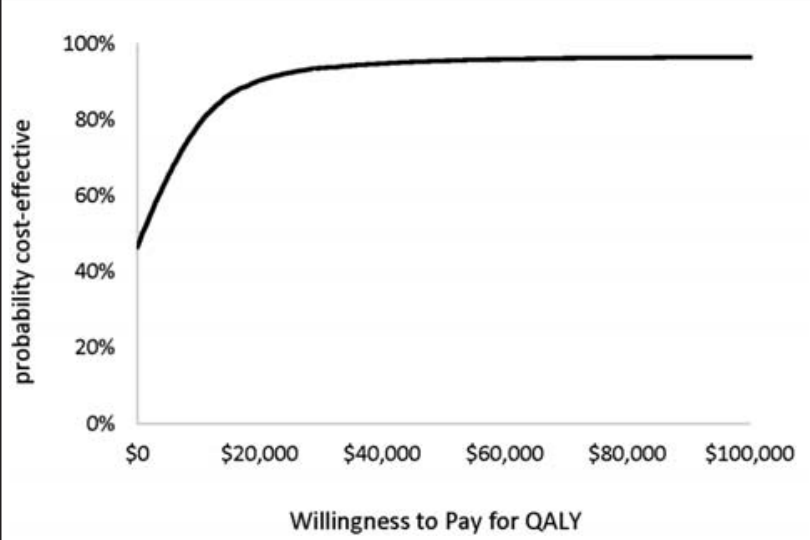

Figure 4. Cost-effectiveness acceptability curve for apixaban versus low-molecular-weight heparin overlapped with vitamin $\mathrm{K}$ antagonist. QALY = quality-adjusted life-years.

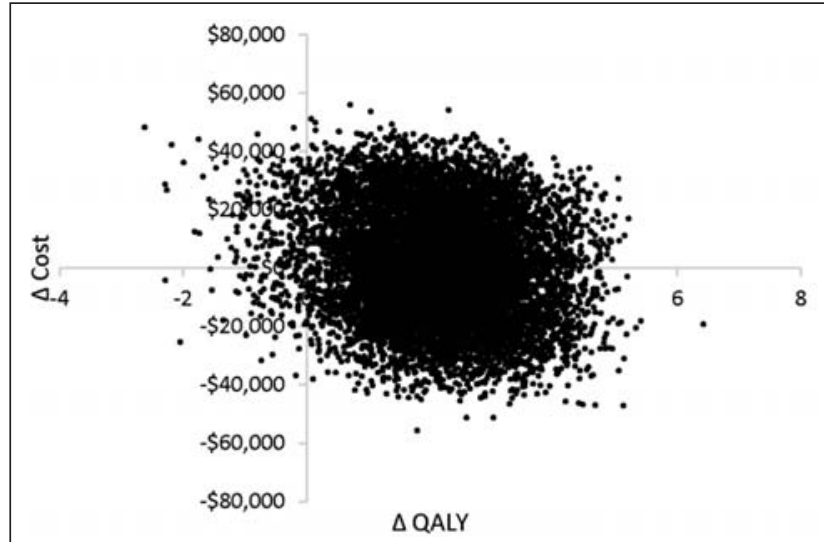

Figure 5. Cost-effectiveness plane for apixaban versus low-molecular-weight heparin overlapped with vitamin $\mathrm{K}$ antagonist. The plane represents cost-effectiveness per 100 patients. QALY = quality-adjusted life-years. study that adverse health events affect patients' utility scores to a greater extent than was assumed in the previous literature. The net effect of these discrepancies is that the current study found apixaban to be more cost-effective than was reported by Klarenbach and others. ${ }^{28}$

In terms of internal validation, the model predictions in the current study were similar to the literature-derived parameter estimates. In terms of external validation, the model predicted a wider range of recurrent VTE than Klarenbach and others. ${ }^{28}$ Although we acknowledge this discrepancy, our values fell within the $95 \%$ confidence intervals reported in a previous study for the population with unprovoked VTE population. ${ }^{29}$ Given that the population with unprovoked VTE was the primary focus of the current study, we concluded that the model was reasonable in its predictions.

One-way sensitivity analysis suggested that short-run fatality rates were the largest drivers of uncertainty in the current analysis. We attributed this uncertainty to small sample sizes, relative to fatality rates, in the previous literature, ${ }^{14-20}$ which resulted in large PSA intervals for these parameters. Additionally, one-way sensitivity analysis suggested that cost-effectiveness results were sensitive to changes in pharmaceutical costs. Subsequently, modest changes in drug prices could yield significantly different costeffectiveness results. Decision-makers should consider relative price differences between pharmaceuticals, if applying these results to their own jurisdictions.

This analysis had several limitations. The length of followup and the ratio of patients with unprovoked VTE to those with provoked VTE were not uniform across the studies used to determine outcome rates. ${ }^{14-20}$ We suspect that the net effect of heterogeneity in the literature informing the current study resulted in understatement of the cost-effectiveness of DOACs. The costs of major bleeding events and recurrent VTE were derived from studies in which patients were using VKAs, and there is uncertainty about the cost of such events for patients using DOACs. Currently, there is inadequate sample size in the existing literature to establish superiority, in terms of efficacy or safety, among various anticoagulant therapy strategies. Future economic analyses would benefit from additional safety and efficacy research. Outcome rates were converted to reflect treatment durations of 6 months, which required assumptions about how outcome events reported in literature would be distributed over the study's follow-up period. This study did not incorporate indirect costs such as missed time at work. We speculate that DOACs would reduce such indirect costs, because they are associated with less patient monitoring than LMWH + VKA.

\section{CONCLUSION}

These findings suggest that apixaban is likely cost-effective for treatment durations of 3, 6, and 12 months. However, for lifetime treatment duration, DOACs are unlikely to be costeffective, because ICERs were significantly above a standard maximum willingness-to-pay per QALY of $\$ 50000$ to $\$ 100000 .{ }^{32}$ Given that the use of DOACs for treatment of VTE is increasing, these findings may help to shape future reimbursement policies.

\section{References}

1. Weinstein MC, Torrance G, McGuire A. QALYs: the basics. Value Health. 2009;12 Suppl 1:S5-9.

2. Detsky AS, Naglie IG. A clinician's guide to cost-effectiveness analysis. Ann Intern Med. 1990;113(2):147-54.

3. Kearon C, Akl EA, Comerota AJ, Prandoni P, Bounameaux H, Goldhaber SZ, et al. Antithrombotic therapy for VTE disease: antithrombotic therapy and prevention of thrombosis, 9th ed: American College of Chest Physicians evidence-based clinical practice guidelines. Chest. 2012;141(2 Suppl): e419S-e496S. 
This single copy is for your personal, non-commercial use only.

For permission to reprint multiple copies or to order presentation-ready copies for distribution, contact CJHP at cjhpedit@cshp.ca

4. Guidelines for the economic evaluation of health technologies: Canada. 3rd ed. Ottawa (ON): Canadian Agency for Drugs and Technologies in Health; 2006.

5. Castellucci LA, Cameron C, Le Gal G, Rodger MA, Coyle D, Wells PS, et al. Clinical and safety outcomes associated with treatment of acute venous thromboembolism: a systematic review and meta-analysis. JAMA. 2014;312(11):1122-35.

6. Diamantopoulos A, Lees M, Wells PS, Forster F, Ananthapavan J, McDonald H. Cost-effectiveness of rivaroxaban versus enoxaparin for the prevention of postsurgical venous thromboembolism in Canada. Thromb Haemostasis. 2010;104(4):760-70.

7. McDonald H, Diamantopoulos A, Wells P, Lees M, Folkerts K, Forster F, Ananthapavan J. Cost-effectiveness of rivaroxaban in the prevention of venous thromboembolism: a Canadian analysis using the Ontario Ministry of Health perspective. J Med Econ. 2012;15(5):817-28.

8. Harrison L, McGinnis J, Crowther M, Ginsberg J, Hirsh J. Assessment of outpatient treatment of deep-vein thrombosis with low-molecular-weight heparin. Arch Intern Med. 1998;158(18):2001-3.

9. Collective agreement between the Capital District Health Authority and the Nova Scotia Government and General Employees Union: Healthcare Bargaining Unit. Halifax (NS): Nova Scotia Health Authority; 2014 [cited 2015 Aug 6]. Available from: www.nshealth.ca/sites/nshealth.ca/files/ central_zone_collective_agreements_health_care_collective_agreement_2011 -2014.pdf

10. Physician's manual. Halifax (NS): Nova Scotia Medical Services Insurance; 2014 [cited 2015 Dec 4]. Available from: www.medavie.bluecross.ca/ static/MSI/PhysicianManual.pdf

11. Patient cost estimator. Ottawa $(\mathrm{ON})$ : Canadian Institute for Health Information; [cited 2015 Dec 24]. Available from: https://www.cihi.ca/ en/spending-and-health-workforce/spending/patient-cost-estimator

12. Ontario case costing initiative (OCCI). Acute inpatient databases for 2005/06 and 2006/07. Toronto (ON): Ministry of Health and Long-Term Care; 2007.

13. Table 326-0021: Consumer price index. In: CANSIM [database]. Ottawa (ON): Statistics Canada.; [cited 2015 Mar 10]. Available from: www.statcan.gc.ca/tables-tableaux/sum-som/101/cst01/econ46a-eng.htm

14. Agnelli G, Buller HR, Cohen A, Curto M, Gallus AS, Johnson M, et al.; AMPLIFY Investigators. Oral apixaban for the treatment of acute venous thromboembolism. N Engl J Med. 2013;369(9):799-808.

15. Schulman S, Kearon C, Kakkar AK, Mismetti P, Schellong S, Eriksson H, et al. Dabigatran versus warfarin in the treatment of acute venous thromboembolism. N Engl J Med. 2009;361(24):2342-52.

16. Schulman S, Kakkar AK, Goldhaber SZ, Schellong S, Eriksson H, Mismetti $\mathrm{P}$, et al. Treatment of acute venous thromboembolism with dabigatran or warfarin and pooled analysis. Circulation. 2014;129(7):764-72.

17. EINSTEIN Investigators; Bauersachs R, Berkowitz SD, Brenner B, Buller HR, Decousus H, Gallus AS, et al. Oral rivaroxaban for symptomatic venous thromboembolism. N Engl J Med. 2010;363(26):2499-510.

18. EINSTEIN-PE Investigators; Büller HR, Prins MH, Lensing AW, Decousus $\mathrm{H}$, Jacobson BF, Minar E, et al. Oral rivaroxaban for the treatment of symptomatic pulmonary embolism. N Engl J Med. 2012;366(14):1287-97.

19. Agnelli G, Buller HR, Cohen A, Curto M, Gallus AS, Johnson M, et al.; AMPLIFY-EXT Investigators. Apixaban for extended treatment of venous thromboembolism. N Engl J Med. 2013;368(8):699-708.

20. Schulman S, Kearon C, Kakkar AK, Schellong S, Eriksson H, Baanstra D, et al.; RE-MEDY Trial Investigators; RE-SONATE Trial Investigators. Extended use of dabigatran, warfarin, or placebo in venous thromboembolism. N Engl J Med. 2013;368(8):709-18.

21. Haentjens P, De Groote K, Annemans L. Prolonged enoxaparin therapy to prevent venous thromboembolism after primary hip or knee replacement. A cost-utility analysis. Arch Orthop Traum Surg. 2004;124(8):507-17.

22. Gould MK, Dembitzer AD, Sanders GD, Garber AM. Low-molecularweight heparins compared with unfractionated heparin for treatment of acute deep venous thrombosis: a cost-effectiveness analysis. Ann Intern Med. 1999;130(10):789-99.
23. Lenert LA, Soetikno RM. Automated computer interviews to elicit utilities: potential applications in the treatment of deep vein thrombosis. J Am Med Inform Assoc. 1997;4(1):49-56.

24. Mahmoudi M, Sobieraj DM. The cost-effectiveness of oral direct factor Xa inhibitors compared with low-molecular-weight heparin for the prevention of venous thromboembolism prophylaxis in total hip or knee replacement surgery. Pharmacotherapy. 2013;33(12):1333-40.

25. Life tables, Canada, provinces and territories: 2010 to 2012 [database online]. Ottawa (ON): Statistics Canada; 2016 [cited 2017 Jan 12]. Available from: www.statcan.gc.ca/pub/84-537-x/84-537-x2016006-eng.htm

26. Flinterman LE, van Hylckama Vlieg A, Cannegieter SC, Rosendaal FR. Long-term survival in a large cohort of patients with venous thrombosis: incidence and predictors. PLoS Med. 2012;9(1):e1001155.

27. Clopper C J, Pearson ES. The use of confidence or fiducial limits illustrated in the case of the binomial. Biometrika. 1934;26(4):404-13.

28. Klarenbach S, Lee K, Boucher M, So H, Manns B, Tonelli M. Direct oral anticoagulants for the treatment of venous thromboembolic events: economic evaluation. Ottawa (ON): Canadian Agency for Drugs and Technologies in Health; 2016.

29. Prandoni P, Noventa F, Ghirarduzzi A, Pengo V, Bernardi E, Pesavento R, et al. The risk of recurrent venous thromboembolism after discontinuing anticoagulation in patients with acute proximal deep vein thrombosis or pulmonary embolism. A prospective cohort study in 1,626 patients. Haematologica. 2007;92(2):199-205.

30. Schulman S, Lindmarker P, Holmström M, Lärfars G, Carlsson A, Nicol P, et al. Post-thrombotic syndrome, recurrence, and death 10 years after the first episode of venous thromboembolism treated with warfarin for 6 weeks or 6 months. J Thromb Haemost. 2006;4(4):734-42.

31. Quon P, Le HH, Raymond V, Mtibaa M, Moshyk A. Clinical and economic benefits of extended treatment with apixaban for the treatment and prevention of recurrent venous thromboembolism in Canada. J Med Econ. 2016;19(6):557-67.

32. Shiroiwa T, Sung YK, Fukuda T, Lang HC, Bae SC, Tsutani K. International survey on willingness-to-pay (WTP) for one additional QALY gained: what is the threshold of cost effectiveness? Health Econ. 2010;19(4):422-37.

Abdullah S Al Saleh, MD, is a Resident in the Department of Medicine, Dalhousie University, Halifax, Nova Scotia.

Patrick Berrigan, MA (Economics), is a Health Economist in the Research Methods Unit, Nova Scotia Health Authority, Halifax, Nova Scotia.

David Anderson, MD, is a Professor in the Department of Medicine, Division of Hematology, and is Dean of the Faculty of Medicine, Dalhousie University, Halifax, Nova Scotia.

Sudeep Shivakumar, MD, is an Associate Professor in the Division of Hematology, Queen Elizabeth II Health Sciences Centre, Halifax, Nova Scotia.

Competing interests: None declared.

\section{Address correspondence to:}

Dr Abdullah S Al Saleh

Department of Medicine

Dalhousie University

Room 483, 1276 South Park St.

Halifax NS B3H 2 Y9

e-mail: Abdullah.s.alsaleh@gmail.com

Funding: None received. 